\section{Comparison of maternal satisfaction between epidural and spinal anesthesia for elective Cesarean section}

Purpose: Epidural anesthesia was a commonly used technique for elective Cesarean section. Recently, because of the availability of non-cutting spinal needles, many institutions have changed from epidural to spinal anesthesia. The purpose of this study was to compare maternal satisfaction between epidural and spinal anesthesia for elective Cesarean section with a new satisfaction tool.

Methods: We studied healthy parturients in a randomized, double-blinded pilot study in which patients were assigned to receive either epidural $(n=13)$ or spinal $(n=14)$ anesthesia for elective Cesarean section. Two and 24 hr postoperatively, patients completed a validated 22-point maternal satisfaction questionnaire and a $10-\mathrm{cm}$ visual analog score (VAS) for satisfaction. Maternal satisfaction scores were compared between groups.

Results: There was no difference in demographics, complications or technical failures between groups. Mean satisfaction scores on the questionnaire (0-154) at two and $24 \mathrm{hr}$ were 130.23 \pm II.36 and I29.54 \pm 16.70 for the epidural group and | |6.92 \pm | 8.47 and | $15.92 \pm 15.7 \mid$ for the spinal group $(P=0.04$ and $P=0.03$ respectively). No difference in VAS scores was noted. The presence of minor side effects including pruritus contributed to the lower satisfaction in the spinal group at $24 \mathrm{hr}$.

Conclusion: This pilot study demonstrated higher maternal satisfaction with epidural than with spinal anesthesia for elective Cesarean section. This may be related to the increased side effects caused by neuraxial morphine. The satisfaction questionnaire was able to elucidate differences not detected with a global VAS for satisfaction. Further study with a larger patient population is required to confirm these data.

Objectif : L'anesthésie péridurale était une technique couramment utilisée pour la césarienne. Récemment, avec l'arrivée des aiguilles mousses, de nombreuses institutions ont préféré la rachianesthésie. La présente étude voulait comparer, avec un nouvel outil de mesure, le degré de satisfaction de la mère pendant la césarienne sous anesthésie péridurale ou rachidienne.

Méthode : Des parturientes en bonne santé ont fait l'objet d'une étude pilote randomisée et à double insu. Elles ont reçu soit une anesthésie péridurale $(n=13)$, soit une rachianesthésie $(n=14)$, pendant une césarienne planifiée. Après l'opération, 2 h et 24 h, la satisfaction des patientes a été évaluée à l'aide d'un questionnaire validé de 22 items et d'une échelle visuelle analogique (EVA) de $10 \mathrm{~cm}$. On a comparé les scores de satisfaction maternelle.

Résultats : Les données démographiques, complications ou défaillances techniques étaient similaires dans les deux groupes. Les scores moyens au questionnaire sur la satisfaction (0-154), $2 \mathrm{~h}$ et $24 \mathrm{~h}$ après l'intervention, ont

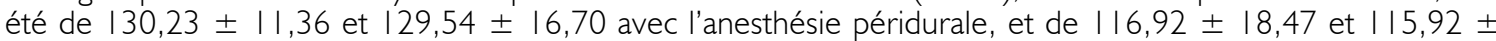
$15,7 \mid$ avec la rachianesthésie ( $P=0,04$ et $P=0,03$ respectivement). Aucune différence de score à l'EVA n'a été notée. Des effets secondaires mineurs, comme le prurit, ont fait baisser le taux de satisfaction $24 \mathrm{~h}$ après la rachianesthésie.

Conclusion : Cette étude pilote a démontré que les mères préfèrent l'anesthésie péridurale à la rachianesthésie pendant la césarienne. Ce qui peut dépendre d'effets secondaires plus importants causés par la morphine médullaire. Le questionnaire sur la satisfaction a mis en évidence des différences non détectées avec l'EVA globale sur le même sujet. Une étude supplémentaire comprenant un grand nombre de patientes demeure nécessaire pour confirmer ces données.

From the Departments of Anesthesia, Mount Sinai Hospital, ${ }^{*}$ and Sunnybrook and Women's College Health Sciences Centre, $\uparrow$ University of Toronto, Toronto, Ontario, Canada.

Address correspondence to: Dr. P. J. Morgan, Department of Anesthesia, Sunnybrook and Women's College Health Sciences Centre, 76 Grenville St. Toronto, Ontario M5S 1B2 Canada. Phone: 416-323-6400 Ext. 4349; Fax: 416-323-6307; E-mail:

pam.morgan@utoronto.ca

Supported by a research scholarship from the Maternal, Infant and Reproductive Health Research Unit (MIRU) at the University of Toronto.

Accepted for publication July 9, 2000. 
T

$\mathrm{H} \mathrm{E}$ renewed interest in spinal anesthesia in obstetrics has led to its routine use for Cesarean section. ${ }^{1}$ Small, non-cutting needles have decreased the incidence of postdural puncture headache making spinal anesthesia feasible in this population. ${ }^{2}$ The advantages of spinal anesthesia include rapid onset of action, low local anesthetic doses and good quality and reliability of the block. ${ }^{1}$ Spinal anesthesia also causes a rapid sympathectomy and hypotension that many women may find distressing. Further, there is no way to reinforce the block if it is found to be inadequate. Epidural anesthesia has the advantage of an indwelling catheter allowing titration of medications with less hemodynamic instability. Disadvantages include the lack of an 'end-point' for detection of the epidural space, the possibility of a 'patchy' or inadequate block, a large dose of administered local anesthetic which has the potential to cause harm if unintentionally administered intravascularly or intrathecally.

Recently, we have developed a tool to measure maternal satisfaction in patients undergoing Cesarean section under regional anesthesia. ${ }^{3}$ The purpose of this study was to determine whether this new tool could detect differences in maternal satisfaction between spinal and epidural anesthesia.

\section{Methods}

After Research Ethics Board Approval and informed consent, ASA I or II women scheduled for elective Cesarean section were enrolled in the study. Exclusion criteria included any contraindication to regional anesthesia or evidence of a poor maternal or fetal condition. An anesthesiologist other than the one administering the anesthetic answered questions relating to the potential risks of the anesthetic technique. Specific differences between the techniques were not discussed in order to maintain blinding. Once patients signed the consent, they were assigned to group A (epidural) or B (spinal) by means of computer-generated randomized numbered sealed envelopes. One of a group of four staff anesthesiologists performed all the anesthetics.

On the day of surgery in the operating room, an 18 or 16 gauge intravenous catheter was placed. Both groups received $10-15 \mathrm{ml} \cdot \mathrm{kg}^{-1}$ balanced salt solution in the 10-15 min before institution of the regional block. Further intravenous fluid boluses were given at the discretion of the attending anesthesiologist. Monitoring included pulse oximetry, ECG, non-invasive blood pressure (NIBP) and a fetal heart rate tracing before and after administration of the block. After two baseline blood pressure measurements, blood pressure was recorded every minute for the first 20 min after local anesthetic administration. Thereafter, the blood pressure was recorded every $2.5 \mathrm{~min}$.

Epidural anesthesia was administered at the $\mathrm{L}_{2.3}$ or $\mathrm{L}_{3}$. ${ }_{4}$ level in the left lateral position using a 16 gauge Tuohy needle with a uniport ( ${ }^{\mathrm{TM}}$ Arrowflex) epidural catheter threaded 4-6 cm into the epidural space. Carbonated lidocaine $2 \%$ with 1:200,000 epinephrine was given through the epidural catheter in 4-5 ml increments (after a 3-ml test dose) until a bilateral $\mathrm{T}_{4}$ level of anesthesia was achieved assessed by loss of sensation to pinprick. Fentanyl, $100 \mu \mathrm{g}$, was given through the catheter after the test dose was administered. Four milligrams epidural morphine were given after delivery of the baby for postoperative analgesia. Spinal anesthesia was achieved at the same lumbar vertebral levels in the left lateral position using a 25 gauge Whitacre needle. After establishing free flow of cerebrospinal fluid, 1.2-1.6 ml hyperbaric bupivacaine $0.75 \%$ (determined by the attending anesthesiologist), $10 \mu \mathrm{g}$ fentanyl and $200 \mu \mathrm{g}$ preservative-free morphine were given. An epidural catheter with the distal end enclosed in a sealed plastic bag was taped to the patient's back and $8 \mathrm{ml}$ normal saline were injected through the catheter after delivery to mimic the administration of epidural morphine in order to blind the data collector. All patients were positioned in the supine position after block administration and left uterine displacement ensured. Prophylactic $10 \mathrm{mg}$ iv ephedrine was given to patients receiving spinal anesthesia once the patient was placed in the supine position.

For both groups, intravenous boluses of ephedrine were administered for a decrease of 5-10\% of baseline mean arterial blood pressure at the discretion of the anesthesiologist. No intravenous opioids were administered. Intravenous benzodiazepines were used only if deemed absolutely necessary for patient anxiety. Metoclopramide $10 \mathrm{mg}$ was given for nausea at the discretion of the attending anesthesiologist.

In order to blind both the data collector and obstetrician to the anesthetic technique employed, they were not allowed to enter the operating room until $30 \mathrm{~min}$ had elapsed from the time of OR entry. During this time, an intravenous catheter was inserted, fluid preload given, monitors applied, the anesthetic administered, fetal heart rate tracings done and a Foley catheter inserted.

The following demographic data were collected: maternal age, height, weight, parity, ethnicity and education history. In addition, the women were asked whether they knew which type of anesthetic they had received.

The primary outcome was the difference in maternal satisfaction between groups. This was measured two and $24 \mathrm{hr}$ after delivery with a previously developed scale. ${ }^{3}$ This satisfaction tool consisted of a 22-point questionnaire with each question ranked from 1-7, l=strongly 
disagree, $7=$ strongly agree with a possible total score of 154. (Figure 1) The questions were clustered into four factors: 1) communication and control 2) anesthetic effects 3) postoperative problems 4) minor side effects. (Figure 2) Satisfaction was also measured at the same time using an unmarked $10 \mathrm{~cm}$ VAS labeled completely unsatisfied at the far left and totally satisfied at the far right. Secondary outcome data collected included: OR entry to T4 block, local anesthetic administration to T4 block (LA: T4 block), OR entry to exit, total dose of ephedrine used, and obstetrician satisfaction.

Maternal satisfaction VAS and questionnaire scores at two and $24 \mathrm{hr}$ were analyzed by two-way analysis of variance. In order to determine which factors were responsible for any differences in global satisfaction seen, the data were further analyzed using unpaired Student $t$ tests. Continuous data (OR entry to T4 block, LA: T4 block, OR entry to exit and ephedrine use) were compared using an unpaired Student's $t$ test. A $P$ value of $<0.05$ was considered statistically significant.

Results

Twenty-seven patients enrolled in the study, 13 in the epidural group and 14 in the spinal group. No patient

Each question is followed by a Likert scale as below.

Strongly disagree
1. I was pain free during my Cesarean section.
2. I felt the anesthetic I received was safe for me.
3. I felt the anesthetic I received was safe for my baby.
4. I had no pain when the needle was put into my back.
5. The needle was put easily into my back.
6. I was in a comfortable position when the needle was put into
my back.

During the Cesarean section, I did NOT experience the following:

7. Shivering

8. Dry lips/mouth

9. Dry throat

10. A change in mood

After the Cesarean section, I did NOT experience:

11. Back Problems

12. Itchiness

In the operating room, during the surgery, I was able to:

13. Interact with my partner

14. Bond with the baby

15. Have a sense of control

16. Communicate with the staff

17. See the baby after delivery

18. Hold the baby after delivery

19. I knew what the staff were doing during the operation.

20. I found the atmosphere in the operating room comfortable.

21. I was able to nurse my baby after delivery

22. I recovered quickly after my Cesarean section.

FIGURE I Maternal Satisfaction Questionnaire dropped out of the study due to inadequate intraoperative analgesia. Demographic data including age, height, weight and parity did not differ between groups. (Table I) There were no technical failures or adverse reactions in any patient. Of the 27 patients, 14 were Caucasian, five Asian, four Hispanic and four African-Americans. Ten patients had completed high school only, 15 had some college or university education and two had postgraduate university education. Most patients were unable to identify correctly the type of regional block received for the Cesarean section. (Table I)

The mean maternal satisfaction score $(0-154,0=$ least satisfied, 154=most satisfied) at two hours was 130.23 \pm 11.36 in the epidural group and $116.92 \pm 18.47$ in the spinal group $(P=0.03)$. At $24 \mathrm{hr}$ mean satisfaction scores were $129.54 \pm 16.70$ for the epidural group and $115.92 \pm 15.71$ for the spinal group $(P=0.04)$. These differences were statistically significant. (Table II) There was no individual item identified to affect the higher satisfaction at two hours. However, factor 4, which included items: dry mouth, dry throat, mood change and pruritus was found to have a negative effect on the 24-hr satisfaction in the spinal group. The VAS scores for satisfaction $(0-10)$ did not differ between groups at either 2 or 24 hr. (Table II)

Secondary outcomes including OR entry to T4 block, local anesthetic to T4 block (LA: $\mathrm{T}_{4}$ block), OR entry to OR exit, ephedrine use and obstetrician satisfaction are summarized in Table II. Onset of anesthesia was faster in the spinal group. No differences were noted between groups for OR entry to $\mathrm{T}_{4}$ block, $\mathrm{OR}$ entry to exit, amount of ephedrine used or obstetrician satisfaction.

The study was halted after 27 patients due to staff re-location and an inability to continue in the same hospital.

\section{Factor 1}

Interaction with Family/Staff

Items: control, baby bonding, seeing and holding baby, knowledgeable about what staff was doing, able to interact with partner and staff

Factor 2

Anesthetic/Technical Effects

Items: easy needle insertion, pain on needle insertion, comfortable position for block, maternal and fetal safety of anesthetic Factor 3 Intra/Postoperative Events

Items: back problems, shivering, comfortable atmosphere, postpartum recovery, ability to nurse baby

Factor 4

Side Effects

Items: dry throat and lips, mood change, pruritus

FIGURE 2 Satisfaction Factors 
TABLE I Demographic Data

\begin{tabular}{lll}
\hline & $\begin{array}{l}\text { Epidural } \\
\text { Anesthesia } \\
n=13\end{array}$ & $\begin{array}{l}\text { Spinal } \\
\text { Anesthesia } \\
n=14\end{array}$ \\
\hline Age $(\mathrm{yr})$ & $34.7 \pm 5.1$ & $31.8 \pm 4.3$ \\
Height $(\mathrm{cm})$ & $158.37 \pm 5.84$ & $158.31 \pm 12.38$ \\
Weight $(\mathrm{kg})$ & $78.81 \pm 10.45$ & $78.18 \pm 9.67$ \\
Nulliparity & $6 / 13$ & $4 / 14$ \\
$\begin{array}{l}\text { Number of women } \\
\text { correctly identifying }\end{array}$ & $3 / 13$ & $4 / 14$ \\
regional block used & & \\
$\begin{array}{l}\text { University education } \\
\text { or higher }\end{array}$ & & \\
\hline
\end{tabular}

Data reported as mean $\pm \mathrm{SD}$

TABLE II Outcome Data

\begin{tabular}{|c|c|c|c|}
\hline & $\begin{array}{l}\text { Epidural } \\
\text { Anesthesia } \\
n=13\end{array}$ & $\begin{array}{l}\text { Spinal } \\
\text { Anesthesia } \\
n=14\end{array}$ & P value \\
\hline $\begin{array}{l}\text { Maternal } \\
\text { Satisfaction: } 2 \mathrm{hr} \\
(0-154)\end{array}$ & $130.23 \pm 11.36$ & $116.92 \pm 18.47$ & 0.03 \\
\hline $\begin{array}{l}\text { Maternal } \\
\text { Satisfaction: } 24 \mathrm{hr} \\
(0-154)\end{array}$ & $129.54 \pm 16.70$ & $115.92 \pm 15.71$ & 0.04 \\
\hline $\begin{array}{l}\text { VAS: } 2 \mathrm{hr} \\
(0-10)\end{array}$ & $8.43 \pm 1.62$ & $8.35 \pm 1.45$ & 0.77 \\
\hline $\begin{array}{l}\text { VAS: } 24 \mathrm{hr} \\
(0-10)\end{array}$ & $8.29 \pm 1.24$ & $8.03 \pm 1.70$ & 0.56 \\
\hline $\begin{array}{l}\text { Obstetrician } \\
\text { Satisfaction (0-10) }\end{array}$ & $9.88 \pm 0.18$ & $9.44 \pm 0.94$ & 0.11 \\
\hline $\begin{array}{l}\text { OR entry: } T_{4} \text { block } \\
(\mathrm{min})\end{array}$ & $29.77 \pm 6.94$ & $24.79 \pm 8.57$ & 0.11 \\
\hline LA: $\mathrm{T}_{4}$ block $(\mathrm{min})$ & $14.36 \pm 3.97$ & $5.73 \pm 4.32$ & 0.0003 \\
\hline $\begin{array}{l}\text { OR entry: OR exit } \\
\text { (min) }\end{array}$ & $90.31 \pm 14.07$ & $89.57 \pm 15.61$ & 0.90 \\
\hline $\begin{array}{l}\text { Ephedrine dosage } \\
\text { (mg) }\end{array}$ & $17.69 \pm 12.85$ & $22.89 \pm 19.16$ & 0.41 \\
\hline
\end{tabular}

Mean \pm SD

\section{Discussion}

Patient satisfaction is an important outcome that is commonly reported. ${ }^{4,5}$ In a healthy obstetric patient population, expectations for an excellent experience are high. Often quality assurance audits of the obstetric experience have included satisfaction parameters, most of which have been based on the technical aspects of care. ${ }^{6}$ Maternal satisfaction is a multidimensional psychological measure that is different from analgesia. ${ }^{4,7-11}$ The development of a reliable and valid satisfaction questionnaire for Cesarean section has allowed the comparison of maternal satisfaction between epidural and spinal anesthesia for elective
Cesarean section. ${ }^{3}$ In addition to being more sensitive than a standard VAS, this tool samples from the various physiological and psychological domains that make up satisfaction, enabling the researcher to pinpoint the aspect of satisfaction that was different between groups.

When the study was designed, we intended to recruit 60 patients. Circumstances arose resulting in the departure of the author, research assistant and two collaborating staff anesthesiologists from the institution where the study was being conducted. Unfortunately, attempts to continue the study at the same hospital were unsuccessful and therefore this paper presents data from a relatively small number of patients.

The purpose of this project was to determine if the satisfaction questionnaire could detect differences in maternal satisfaction between epidural and spinal anesthesia for Cesarean section. Analyses of the data demonstrated higher maternal satisfaction with epidural anesthesia for Cesarean section when assessed at two and $24 \mathrm{hr}$ postoperatively. When the factors affecting satisfaction were examined, no single factor was found to affect independently the higher satisfaction with epidural anesthesia at two hours. However, at $24 \mathrm{hr}$, factor 4 , which included four items, pruritus, mood change, dry throat and dry mouth was responsible for the difference in maternal satisfaction. These findings contrast with those of Davies et al. who reported higher satisfaction scores in women receiving combined spinal-epidural anesthesia (CSEA) vs epidural anesthesia (EA) for elective Cesarean section. ${ }^{2}$ However, satisfaction in this study was based on anxiety and pain relief at different points during the operative procedure and a global VAS for satisfaction related to these events obtained 24 hr postpartum. Patients were asked to include pruritus as a part of their 24-hr satisfaction score.

There are numerous studies that have assessed maternal satisfaction in labour. ${ }^{8,9,13-21}$ It is generally agreed that satisfaction, a multi-dimensional psychological outcome, is not easily evaluated or defined. The VAS, although useful for 1-item measurement, is not particularly helpful for multidimensional outcomes. ${ }^{9,22,23}$ Determination of satisfaction using a VAS has limitations in that it does not give any information of the individual factors affecting satisfaction in general. ${ }^{3}$ This impairs the ability to make strategic changes to improve the procedure being assessed. In our study, no differences were noted between the VAS for satisfaction between groups. However, using the satisfaction questionnaire, differences were noted at two and $24 \mathrm{hr}$ with the lower 24-hr satisfaction in the spinal group related to the presence of pruritus. This finding 
supports the use of this satisfaction tool since, even in a small population, it appears to be more sensitive in the detection of differences than the global VAS for satisfaction and enables the reason for the difference to be determined.

The anesthetic regimens used in this study allowed the attending anesthesiologist some flexibility related to the dose of spinal bupivacaine but doses of intrathecal and epidural morphine were the same for all patients $(4 \mathrm{mg}$ epidural morphine and $200 \mu \mathrm{g}$ spinal morphine). The $24-\mathrm{hr}$ difference in satisfaction that appeared to be related to pruritus was an interesting finding. A recent article by Palmer and co-workers reports that side effects such as pruritus did not differ among patients receiving $1.25,2.5,3.75$ or $5 \mathrm{mg}$ of epidural morphine after Cesarean section. ${ }^{24}$ The authors also found that the threshold for pruritus appeared to be quite low $(1.25 \mathrm{mg})$. This finding is in contrast to the well-described dose-related pruritus seen with intrathecal morphine. ${ }^{25,26}$ Having noted the difference in satisfaction related to this side effect in this study, smaller doses of spinal morphine could be used to improve satisfaction in this patient population.

The resurgence of interest and use of spinal anesthesia for elective Cesarean section has stemmed from the fact that many of the problems associated with the technique in the past have been overcome. Post-dural puncture headache is now very uncommon with an incidence of $<1 \%$ with small gauge pencil-point spinal needles. ${ }^{2}$ Hypotension commonly accompanies the sympathetic blockade associated with spinal anesthesia. Fluid preload, prophylactic ephedrine and the maintenance of left uterine displacement help offset this effect. ${ }^{27-29}$ The advantages of the technique including the rapid onset and quality of the block make this an attractive reason to use spinal anesthesia for elective Cesarean section. Local anesthetic overdose or inadvertent intravascular or intrathecal injection of a large dose of local anesthetic, as can occur with epidural anesthesia, can be avoided if spinal anesthesia is used. Many obstetric anesthesiologists routinely use spinal anesthesia for elective Cesarean section. Obstetricians appreciate the faster onset of the block since turnover time is shorter and cost savings may occur. ${ }^{30}$ This study supports the faster onset of anesthesia with the time from local anesthetic administration to $\mathrm{T}_{4}$ block with spinal anesthesia. It is also interesting to note, that, when blinded, obstetrician satisfaction was excellent and did not differ between techniques, indicating that surgical conditions were equally acceptable.

Physicians' beliefs that spinal anesthesia is the method of choice, disregards patient preference. Data collected in this study suggest that, in our setting, using the dose and drugs outlined here, patients may prefer epidural anesthesia. With a larger cohort of patients, these findings could be confirmed and more factors may surface. With this information, alterations in drugs or doses or attention to prophylactic measures to avoid side effects could be instituted and may improve maternal satisfaction. Nonetheless, when the actual satisfaction scores are examined, virtually all the women were satisfied with their anesthetic.

This pilot project demonstrated that a new satisfaction tool is able to differentiate differences in maternal satisfaction that are not seen using a global VAS for satisfaction. The differences appeared to be related to postoperative pruritus in the spinal group. Further study with a larger population is required to confirm these preliminary findings and to confirm the factors responsible for these differences.

\section{Acknowledgments}

The authors would like to acknowledge the support of Drs. Castro, Morningstar, Rolbin and Ms. Jana Evers.

\section{References}

1 Morgan P. Spinal anaesthesia in obstetrics. Can J Anaesth 1995; 42: 1145-63.

2 Halpern S, Preston R Postdural puncture headache and spinal needle design. Anesthesiology 1994; 81: 1376-83.

3 Morgan PJ, Halpern S, Lo J. The development of a maternal satisfaction scale for Caesarean section. Int J Obstet Anesth 1999; 8: 165-70.

4 Robinson PN, Salmon P, Yentis SM. Maternal satisfaction. Int J Obstet Anesth 1998; 7: 32-7.

5 Fung D, Cohen MM. Measuring patient satisfaction with anesthesia care: a review of current methodology. Anesth Analg 1998; 87: 1089-98.

6 Pagenkopf D, Davies JM, Bahan M, Cuppage A A complementary approach to outcome analysis in the parturient. Quality Assurance in Health Care 1991; 3: 241-5.

7 Halpern SH, Morgan PJ. Measuring patient satisfaction in obstetric anesthesia. Current Anesthesiology Reports 2000; 2 : 13-7.

8 Slade P, MacPherson SA, Home A, Maresh M. Expectations, experiences and satisfaction with labour. Br J Clin Psychol 1993; 32: 469-83.

9 Waldenström U, Borg I-M, Olsson B, Sköld M, Wall S. The childbirth experience: a study of 295 new mothers. Birth 1996; 23: 144-53.

10 Salmon P, Miller R, Drew NC. Women's anticipation and experience of childbirth: the independence of fulfilment, unpleasantness and pain. Br J Med Psychol 1990; 63: 255-9. 
11 Fitzpatrick $R$ Surveys of patient satisfaction: I - important general considerations. BMJ 1991; 302: 887-9.

12 Davies SJ, Paech MJ, Welch H, Evans SF, Pavy TJG Maternal experience during epidural or combined spinal-epidural anesthesia for Cesarean section: a prospective, randomized trial. Anesth Analg 1997; 85: 607-13.

13 Kirke PN. Mothers' views of obstetric care. Br J Obstet Gynaecol 1980; 87: 1029-33.

14 Séguin L, Therrien R, 'Champagne F, Larouche D The components of women's satisfaction with maternity care. Birth 1989; 16: 109-13.

15 Green JM, Coupland VA, Kitzinger JV. Expectations, experiences, and psychological outcomes of childbirth: a prospective study of 825 women. Birth 1990; 17: 15-23.

16 Paech MJ. The King Edward Memorial Hospital 1000 mother survey of methods of pain relief in labour. Anaesth Intensive Care 1991; 19: 393-9.

17 Murphy JD, Henderson K, Bowden MI, Lewis M, Cooper $G M$. Bupivacaine versus bupivacaine plus fentanyl for epidural analgesia: effect on maternal satisfaction. BMJ 1991; 302: 564-7.

18 Brown S, Lumley J. Satisfaction with care in labor and birth: a survey of 790 Australian women. Birth 1994; 21: 4-13.

19 Ranta $P$, Spalding M, Kangas-Saarela T, et al. Maternal expectations and experiences of labour pain options of 1091 Finnish parturients. Acta Anaesthesiol Scand 1995; 39: 60-6.

20 Mould TAJ, Chong S, Spencer JAD, Gallivan S.

Women's involvement with the decision preceding their Caesarean section and their degree of satisfaction. Br J Obstet Gynaecol 1996; 103: 1074-7.

21 Drew NC, Salmon P, Webb L. Mothers', midwives' and obstetricians' views on the features of obstetric care which influence satisfaction with childbirth. Br J Obstet Gynaecol 1989; 96: 1084-8.

22 Lomas J, Dore S, Enkin M, Mitchell $A$ The labor and delivery satisfaction index: the development and evaluation of a soft outcome measure. Birth 1987; 14: 125-9.

23 Hundley VA, Milne JM, Glazener CMA, Mollison J. Satisfaction and the three C's: continuity, choice and control. Women's views from a randomised controlled trial of midwife-led care. Br J Obstet Gynaecol 1997; 104: 1273-80.

24 Palmer CM, Nogami WM, Van Maren G, Alves DM. Postcesarean epidural morphine: a dose-response study. Anesth Analg 2000; 90: 887-91.

25 Palmer CM, Emerson S, Volgoropolous D, Alves D. Doseresponse relationship of intrathecal morphine for postcesarean analgesia. Anesthesiology 1999; 90: 437-44.

26 Dabl JB, Jeppesen IS, Jorgensen H, Wetterslev J, Møiniche $S$. Intraoperative and postoperative analgesic efficacy and adverse effects of intrathecal opioids in patients undergoing Cesarean section with spinal anesthesia. Anesthesiology 1999; 91: 1919-27.

27 Morgan PJ, Halpern S, Tarshis J. Crystalloid preload before spinal anesthesia for elective Cesarean section: a meta-analysis. Anesthesiology 1999; 91(Suppl): A33.

28 Gutsche BB. Prophylactic ephedrine preceding spinal analgesia for Cesarean section. Anesthesiology 1976; 45: 462-5.

29 Rout CC, Rocke DA. Prevention of hypotension following spinal anesthesia for Cesarean section. Int Anesthesiol Clin 1994; 32: 117-35.

30 Riley ET, Cohen SE, Macario A, Desai JB, Ratner EF. Spinal versus epidural anesthesia for Cesarean section: a comparison of time efficiency, costs, charges, and complications. Anesth Analg 1995; 80: 709-12. 